Original

\title{
Cytotoxicity evaluation of methacrylate-based resins for clinical endodontics in vitro
}

\author{
Esteban G. Garza1), Aniket Wadajkar2), Chul Ahn'), Qiang Zhu), Lynn A. Opperman5), \\ Larry L. Bellinger ${ }^{5)}$, Kytai T. Nguyen²) and Takashi Komabayashi6) \\ 1)Community Dental Care Clinic, Dallas, TX, USA \\ 2)Department of Bioengineering, University of Texas Arlington, Arlington, TX, USA \\ 3)Department of Clinical Science, University of Texas Southwestern Medical Center at Dallas, Dallas, TX, USA \\ 4)Division of Endodontology, University of Connecticut Health Center, Farmington, CT, USA \\ ${ }^{5)}$ Department of Biomedical Sciences, Texas A\&M Health Science Center, Baylor College of Dentistry, \\ Dallas, TX, USA \\ 6)Department of Endodontics, Texas A\&M Health Science Center, Baylor College of Dentistry, \\ Dallas, TX, USA
}

(Received 12 January and accepted 7 March 2012)

\begin{abstract}
This study examines the cytotoxicity of Super-Bond C\&B (SB-C\&B), Super-Bond RC Sealer (SB-RC), MetaSEAL (Meta), and AH Plus Sealer $(\mathrm{AH}+)$. Freshly mixed and set materials $(100 \mathrm{mg})$ were prepared in vitro and placed in cell culture medium ( 1 $\mathrm{mL}$ ) for the working time and for $6 \mathrm{~h}$, respectively. L929 cells seeded into 96-well plates at 5,000 cells/ well were incubated with the eluted medium $(200 \mu \mathrm{L})$ for $24 \mathrm{~h}$. Cells cultured with medium alone served as the control. Cytotoxicity was evaluated by MTS assay and analyzed with ANOVA. In the freshly mixed group, the average \pm SD $(\%)$ for cell viability were 66.0 $\pm 13.6,55.5 \pm 15.6,10.6 \pm 0.7$, and $8.9 \pm 2.2$ for SB-C\&B, SB-RC, Meta, and AH+, respectively. In the set group, the average \pm SD (\%) for cell viability were $100 \pm 21.9,81.8 \pm 38.5,24.9 \pm 7.9$, and $23.6 \pm 10.0$ for SB-C\&B, SB-RC, Meta, and AH+, respectively. SB-C\&B and SB-RC are less cytotoxic than are Meta and AH+. (J Oral Sci 54, 213-217, 2012)
\end{abstract}

Correspondence to Dr. Takashi Komabayashi, Department of Endodontics, Texas A\&M Health Science Center Baylor College of Dentistry, 3302 Gaston Avenue, Dallas, TX 75246 USA

Tel: +1-214-828-8365

Fax: +1-214-874-4507

E-mail: tkomabayashi@bcd.tamhsc.edu \& ICD38719@nifty.com
Keywords: cytotoxicity; methacrylate; resin; sealer; endodontics.

\section{Introduction}

Over 22 million root canal treatments are performed each year in the United States (1). Sealers in combination with a solid or semi-solid core material are used to fill voids and to seal canals during obturation. The apical seal, like the coronal seal, is critical for long-term clinical success (2). Some studies report the apical seals of resinbased sealers to be superior to those of other sealers $(3,4)$. Thus, various resin sealers have been commercialized for endodontic applications (5-8).

Among resin sealers, the epoxy resin sealer, $\mathrm{AH}$ Plus $(\mathrm{AH}+)$, is conventionally used (9). Recently, two methacrylate resin sealers have been introduced. One is the methacrylate/sulfinate salt (MA/SS)-based resin sealer, MetaSEAL (Meta). The other is methyl methacrylate/tributylborane (MMA/TBB)-based resin sealer, Super-Bond RC Sealer (SB-RC), which was developed to address Super-Bond C\&B (SB-C\&B) resin cement's drawbacks: short working time, low radiopacity, and difficult removal of the material from the canal (10). The polymer components of SB-RC are poly(methyl methacrylate) (PMMA) and zirconium oxide, while that 
of SB-C\&B is PMMA.

Materials for endodontic applications must not only provide good seals, but also exhibit excellent biocompatibility, because cytotoxicity of tissues is of concern when materials are involved with human tissue (11). Although biocompatibility is one of the factors that influence the clinician's choice of sealers in root canal therapy $(12,13)$, cytotoxicity studies of methacrylate-based resins in fresh and set conditions are limited.

The purpose of this study therefore was to examine the cytotoxicity of SB-C\&B, SB-RC, Meta, and AH+. L929 cells were used due to their sensitivity to toxic products, which explains their frequent use in the evaluation of root canal sealers (14).

\section{Materials and Methods \\ Materials}

The resin cement and three root canal sealers tested in this study were 1) Super-Bond C\&B (Sun Medical Co., Shiga, Japan) (in the United States, C\&B Metabond [Parkell, Edgewood, NY]), 2) Super-Bond RC Sealer (Sun Medical, Japan), 3) MetaSEAL (Parkell, Edgewood, NY) (In Japan, Hybrid Root SEAL [Sun Medical Co., Shiga, Japan]), and 4) AH Plus (Dentsply DeTrey, Konstanz, Germany). Lot numbers, working lengths, setting times, and classifications are summarized in Table 1.

L929 mouse fibroblasts were obtained from American Type Culture Collection (ATCC, Manassas, VA, USA). Cells were grown in Dulbecco's Modified Eagle Medium (DMEM) (Invitrogen, Grand Island, NY, USA), supplemented with $10 \%$ fetal bovine serum (Hyclone Laboratories Inc., Logan, UT, USA), and $1 \%$ penicillinstreptomycin (Gibco BRL, Gaithersburg, MD, USA) under standard cell culture conditions $\left(37^{\circ} \mathrm{C}\right.$ and $5 \%$ $\mathrm{CO} 2)$.

\section{Methods}

The cytotoxicity of the four materials was tested for both fresh and set sealer samples. L929 cells were seeded into 96-well plates at 5,000 cells/well and incubated for $24 \mathrm{~h}$ to allow adhesion for the cell cytotoxicity assay.

Samples of freshly (immediately) mixed materials were placed into 24-well plates at approximately $0.1 \mathrm{~g} /$ well. The fresh materials were mixed according to the manufacturers' instructions. Then $1 \mathrm{~mL}$ cell culture medium was added to the wells. After the required working time (specified in Table 1), the medium was removed and added $(200 \mu \mathrm{L})$ to the cells prior to their 24-h incubation.

To obtain the set materials, samples of the different materials (setting time specified in Table 1) were placed into a 24 -well plate at approximately $0.1 \mathrm{~g} /$ well and incubated for $24 \mathrm{~h}$ in the cell culture incubator to allow for setting. Then $1 \mathrm{~mL}$ of the cell culture medium was added to the set materials and left for $6 \mathrm{~h}$. Every hour, wells were shuffled for 5 s. $200 \mu \mathrm{L}$ of the material eluate from the different eluate groups was added to the cell culture wells.

In both the fresh and set material groups, after an incubation period of $24 \mathrm{~h}$ at $37^{\circ} \mathrm{C}, 200 \mu \mathrm{L}$ of MTS reagent was added to the cell culture wells, and cell viability was evaluated according to the manufacturer's instructions. Cells cultured with the medium only served as the control group (100\%). Each experiment was repeated four times.

\section{Data analysis and statistics}

An ANOVA test was conducted to determine whether there were significant differences in cell viability between the experimental and the control groups, and Student's $t$-tests were conducted to identify which material was significantly different from control with Dunnett's correction.

\section{Results}

When cells were cultured with the eluates of the fresh materials, the average $\pm \mathrm{SD}$ values $(\%)$ for biocompatibility were $66.0 \pm 13.6,55.5 \pm 15.6,10.6 \pm 0.7$, and 8.9 \pm 2.2 for SB-C\&B, SB-RC, Meta, and $\mathrm{AH}+$, respectively. The results for Meta $(P=0.0024)$ and $\mathrm{AH}+(P=0.0005)$ showed statistical significance when compared with the control (Fig. 1). The cell viability in the Meta and $\mathrm{AH}+$ groups was significantly less than that in the SB-C\&B and SB-RC groups $(P<0.05)$. There was no statistically significant difference between SB-C\&B and SB-RC, or between Meta and $\mathrm{AH}+$.

When cells were cultured with eluate of the set materials, the average $\pm \mathrm{SD}$ values $(\%)$ for biocompatibility were $100 \pm 21.9,81.8 \pm 38.5,24.9 \pm 7.9$, and $23.6 \pm$ 10.0 for SB-C\&B, SB-RC, Meta, and $\mathrm{AH}+$, respectively (Fig. 2). The viability of cells cultured with SB-C\&B and SB-RC eluates was significantly higher than that of cells cultured with eluates of Meta and $\mathrm{AH}+(P<0.05)$. There was no statistically significant difference between SB-C\&B and SB-RC, and between Meta and $\mathrm{AH}+$. The cell viability in the SB-C\&B and SB-RC groups was significantly higher than that in the Meta and $\mathrm{AH}+$ groups $(P<0.05)$.

\section{Discussion}

In our study, AH plus was found to be the most cytotoxic of the sealers. AH plus is a two-component system consisting of two pastes. The epoxide paste contains 


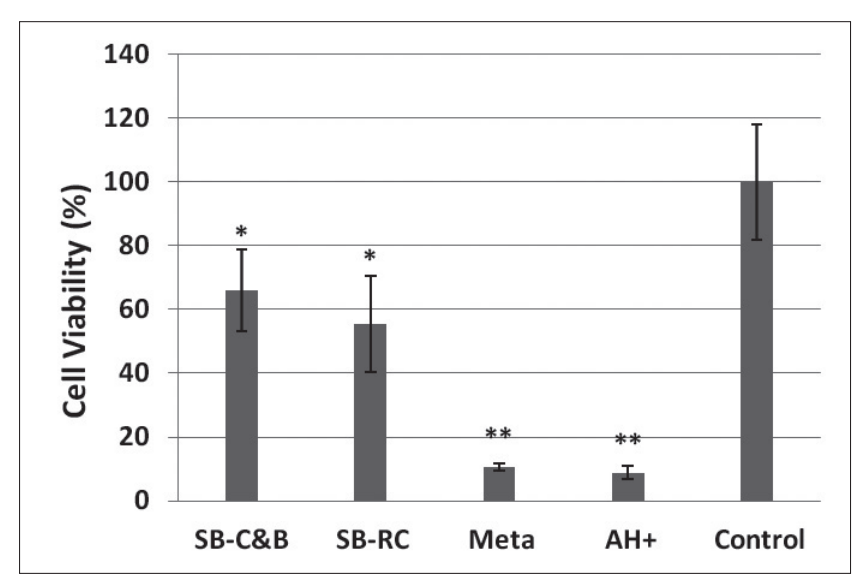

Fig. 1 Cell viability of L929 cells after culture with elute of fresh materials.

*Significant difference from the control, Meta and $\mathrm{AH}+$ groups. **Significant difference from the control, SB-C\&B and SB-RC groups.

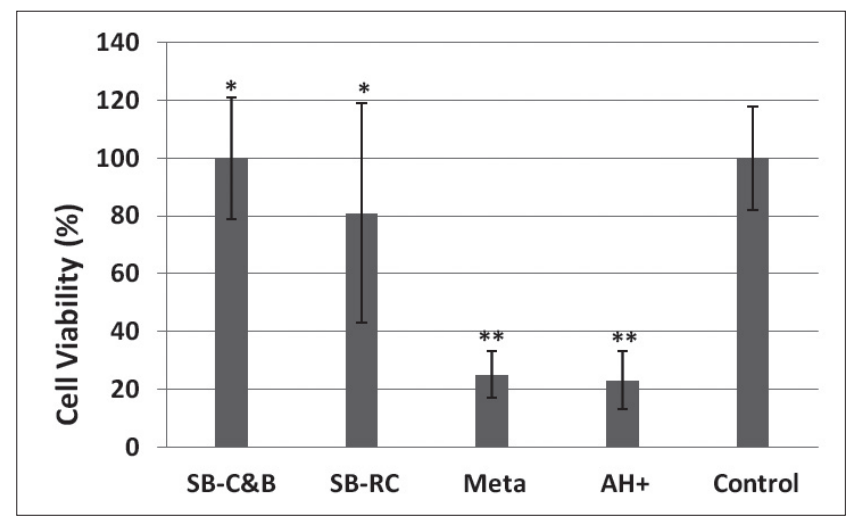

Fig. 2 Cell viability of L929 cells after culture with elute of set materials.

*Significant difference from the control, Meta and $\mathrm{AH}+$ groups. **Significant difference from the control, SB-C\&B and SB-RC groups.

diepoxide. The amine paste contains 1-adamantane amine, T N,N'-dibenzyl-5-oxa-nonandiamine-1,9, and TCD-diamine. When the two pastes are mixed, the poly addition reaction starts immediately. The amines polymerize with the diepoxide to co-polymers. The un-polymerized monomers which were eluted to the medium during setting cause the cytotoxic effect. AH 26 releases formaldehyde and exhibits cytotoxicity (15-20). Comparing with AH 26 only a minimum release of formaldehyde from AH plus was observed (16). AH 26 and $\mathrm{AH}$ plus both demonstrated cytotoxicity in rat cerebral astrocyte cell culture (21). AH plus was more cytotoxic than AH 26 in human cervical carcinoma cells and mouse skin fibroblasts (22). AH Plus has shown to be cytotoxic in the first three days and does not reach non-cytotoxicity until 3 to 5 weeks (23). The results of the present experiment are in agreement with the previous studies. However, studies have shown AH plus exhibiting close to no cytotoxicity $(24,25)$. These differences may due to the differences in experimental conditions and methods.

Meta was found to be very cytotoxic, especially when fresh. These results have been found in similar studies on the cytotoxic effects of Meta $(23,26)$. Meta's monomer components include 4-methacryloxyethyl trimellitate anhydride (4-META) and hydroxyethyl methacrylate (HEMA). Based on 50\% inhibition of cell growth, the relative cytotoxicity of the monomers MMA : 4-META : HEMA was calculated as 1:6:7 $(27,28)$. It is thought that HEMA diffuses through dentine to cause cellular damage $(29,30)$. HEMA also induces cell growth inhibition and cycle perturbation as well as glutathione depletion and reactive oxygen species production (31).

HEMA has been reported to inhibit intracellular tyrosine phosphorylation in L929 cells (32). These are reasonable explanations for our cytotoxicity results for Meta.

The main monomer component of SB-C\&B and SB-RC is MMA, which has a low potential for pulp irritation compared with other poly-functional methacrylate monomers $(27,33)$. The polymerization initiator of SB-C\&B and SB-RC is TBB. Tronstad et al. studied pulp responses to composite resin (Concise) and MMATBB-based resin (Polycap) in deep Class V cavities in monkeys after 8 days (34). In composite resin, 30\% of responses were slight; $50 \%$, moderate; and $20 \%$, severe. In MMA/TBB-based resin, $75 \%$ of responses were slight; $25 \%$, moderate; and $0 \%$, severe. Overall, the MMA/TBB-based resin had lower cytotoxicity than did the composite resin. No severe response to the MMA/ TBB-based resin was reported.

The success of MMA/TBB-based resin in endodontic applications can be attributed to several material properties. MMA is the least cytotoxic among the monomers used in dentistry $(27,35,36)$. Also, the residual MMA is low after setting and decreases with time because of the presence of TBB (37). Finally, the polymerization at the dentin interface enables reliable sealing of the interface due to the presence of TBB (38).

Several studies have indicated that cytotoxic effects in cell culture can be caused by released monomers $(39,40)$. The curing of resin-based cement is usually not complete, so unconverted monomers can be released from the resin into an adjacent aqueous phase and can diffuse through dentin to the pulp space. In short, before setting, the cytotoxicity of the monomer itself will affect the pulp, while after setting, the residual effect of the monomer will depend on amount and elution kinetics. In this regard, in 
addition to the low cytotoxicity of the MMA in SB-C\&B and SB-RC, the TBB initiator significantly reduced the residual MMA during the course of the resin's setting (37). Our data are consistent with those of a similar study that found minimal cytotoxic effects with SB-RC (41). Although the results of our in vitro study are significant and offer good clinical information, it is necessary to confirm the in vitro results with future in vivo studies.

This study demonstrates that the MMA/TBB resins SB-C\&B and SB-RC are less cytotoxic than are Meta and $\mathrm{AH}+$. While excellent sealing of the canal has been reported with MMA/TBB resins $(10,17), \mathrm{SB}-\mathrm{C} \& \mathrm{~B}$ is not suitable for root canal use due to its poor handling properties. Therefore, among all tested materials, SB-RC's low cytotoxicity and excellent sealing of the canal at the resin-dentin interface recommend it for clinical use.

\section{Acknowledgments}

This paper was supported in part by NIH KL2 RR024983(TK) and UL1 RR024982. Dr. Komabayashi is a consultant for Sun Medical.

\section{References}

1. American Dental Association. 2005-6 Survey of dental services rendered and distribution of dentists in the United States by region and state. ADA Survey Center, Chicago.

2. Shipper G, Ørstavik D, Teixeira FB, Trope M (2004) An evaluation of microbial leakage in roots filled with a thermoplastic synthetic polymerbased root canal filling material (Resilon). J Endod 30, 342-347.

3. Limkangwalmongkol S, Burtscher P, Abbott PV, Sandler AB, Bishop BM (1991) A comparative study of the apical leakage of four root canal sealers and laterally condensed gutta-percha. J Endod 17, 495-499.

4. Oguntebi BR, Shen C (1992) Effect of different sealers on thermoplasticized Gutta-percha root canal obturations. J Endod 18, 363-366.

5. Cobankara FK, Orucoglu H, Sengun A, Belli S (2006) The quantitative evaluation of apical sealing of four endodontic sealers. J Endod 32, 66-68.

6. Belli S, Ozcan E, Derinbay O, Eldeniz AU (2008) A comparative evaluation of sealing ability of a new, self-etching, dual-curable sealer: hybrid root SEAL (MetaSEAL). Oral Surg Oral Med Oral Pathol Oral Radiol Endod 106, e45-52.

7. Stoll R, Thull P, Hobeck C, Yüksel S, JablonskiMomeni A, Roggendorf MJ, Frankenberger R (2010) Adhesion of self-adhesive root canal sealers on gutta-percha and Resilon. J Endod 36, 890-893.

8. Yamanaka Y, Shigetani Y, Yoshiba K, Yoshiba $\mathrm{N}$, Okiji $\mathrm{T}$ (2011) Immunohistochemical analysis of subcutaneous tissue reactions to methacrylate resin-based root canal sealers. Int Endod J 44, 669-675.

9. Pameijer CH, Zmener O (2010) Resin materials for root canal obturation. Dent Clin North Am 54, 325-344.

10. Imai Y, Komabayashi T (2003) Properties of a new injectable type of root canal filling resin with adhesiveness to dentin. J Endod 29, 20-23.

11. Bertram JS (2000) The molecular biology of cancer. Mol Aspects Med 21, 167-223.

12. Geurtsen W, Leyhausen G (1997) Biological aspects of root canal filling materials - histocompatibility, cytotoxicity, and mutagenicity. Clin Oral Investig 1, 5-11.

13. Dahl JE (2005) Toxicity of endodontic filling materials. Endodontic Topics 12, 39-43.

14. Pissiotis E, Spångberg LS (1991) Toxicity of Pulpispad using four different cell types. Int Endod J 24, 249-257.

15. Spångberg LS, Barbosa SV, Lavigne GD (1993)AH 26 releases formaldehyde. J Endod 19, 596-598.

16. Cohen BI, Pagnillo MK, Musikant BL, Deutsch AS (1998) Formaldehyde evaluation from endodontic materials. Oral Health 88, 37-39.

17. Leonardo MR, Bezerra da Silva LA, Filho MT, Santana da Silva R (1999) Release of formaldehyde by 4 endodontic sealers. Oral Surg Oral Med Oral Pathol Oral Radiol Endod 88, 221-225.

18. Merdad K, Pascon AE, Kulkarni G, Santerre P, Friedman S (2007) Short-term cytotoxicity assessment of components of the epiphany resin-percha obturating system by indirect and direct contact millipore filter assays. J Endod 33, 24-27.

19. Lodiene G, Morisbak E, Bruzell E, Ørstavik D (2008) Toxicity evaluation of root canal sealers in vitro. Int Endod J 41, 72-77.

20. Donadio M, Jiang J, He J, Wang YH, Safavi KE, Zhu Q (2009) Cytotoxicity evaluation of Activ GP and Resilon sealers in vitro. Oral Surg Oral Med Oral Pathol Oral Radiol Endod 107, e74-78.

21. Huang TH, Yang JJ, Li H, Kao CT (2002) The biocompatibility evaluation of epoxy resin-based root canal sealers in vitro. Biomaterials 23, 77-83.

22. Miletić I, Anić I, Karlović Z, Marsan T, Pezelj-Ribarić S, Osmak M (2000) Cytotoxic effect of four root filling materials. Endod Dent Traumatol 16, 287-290. 
23. Pinna L, Brackett MG, Lockwood PE, Huffman BP, Mai S, Cotti E, Dettori C, Pashley DH, Tay FR (2008) In vitro cytotoxicity evaluation of a self-adhesive, methacrylate resin-based root canal sealer. J Endod 34, 1085-1088.

24. Leyhausen G, Heil J, Reifferscheid G, Waldmann P, Geurtsen W (1999) Genotoxicity and cytotoxicity of the epoxy resin-based root canal sealer $\mathrm{AH}$ plus. J Endod 25, 109-113.

25. Camps J, About I (2003) Cytotoxicity testing of endodontic sealers: a new method. J Endod 29, 583-586.

26. Ames JM, Loushine RJ, Babb BR, Bryan TE, Lockwood PE, Sui M, Roberts S, Weller RN, Pashley DH, Tay FR (2009) Contemporary methacrylate resin-based root canal sealers exhibit different degrees of ex vivo cytotoxicity when cured in their self-cured mode. J Endod 35, 225-228.

27. Yoshii E (1997) Cytotoxic effects of acrylates and methacrylates: relationships of monomer structures and cytotoxicity. J Biomed Mater Res 37, 517-524.

28. Imazato S, Tarumi H, Ebi N, Ebisu S (2000) Cytotoxic effects of composite restorations employing self-etching primers or experimental antibacterial primers. J Dent 28, 61-67.

29. Bouillaguet S, Wataha JC, Hanks CT, Ciucchi B, Holz J (1996) In vitro cytotoxicity and dentin permeability of HEMA. J Endod 22, 244-248.

30. Hume WR, Gerzina TM (1996) Bioavailability of components of resin-based materials which are applied to teeth. Crit Rev Oral Biol Med 7, 172-179.

31. Chang HH, Guo MK, Kasten FH, Chang MC, Huang GF, Wang YL, Wang RS, Jeng JH (2005) Stimulation of glutathione depletion, ROS production and cell cycle arrest of dental pulp cells and gingival epithelial cells by HEMA. Biomaterials 26, 745-753.

32. Kaga M, Noda M, Ferracane JL, Nakamura W,
Oguchi H, Sano H (2001) The in vitro cytotoxicity of eluates from dentin bonding resins and their effect on tyrosine phosphorylation of L929 cells. Dent Mater 17, 333-339.

33. Fujisawa S, Atsumi T (2004) Cytotoxicities of a 4-META/MMA-TBBO resin against human pulp fibroblasts. Dent Mater J 23, 106-108.

34. Tronstad L, Spångberg L (1974) Biologic tests of a methyl methacrylate composite material. Scand J Dent Res 82, 93-98.

35. Imai Y, Watanabe M, Lee HE, Kojima K, Kadoma Y (1988) Cytotoxicity of monomers used in dental resins. Iyo Kizai Kenkyujo Hokoku 22, 87-90. (in Japanese)

36. Takeda S, Hashimoto Y, Miura Y, Kimura Y, Nakamura M (1993) Cytotoxicity test of dental monomers using serum-free cell culture (in vitro). Shika Zairyo Kikai 12, 613-619. (in Japanese)

37. Hirabayashi C, Imai Y (2002) Studies on MMA-TBB resin. I. Comparison of TBB and other initiators in the polymerization of PMMA/MMA resin. Dent Mater J 21, 314-321.

38. Imai Y, Kadoma Y, Kojima K, Akimoto T, Ikakura K, Ohta T (1991) Importance of polymerization initiator systems and interfacial initiation of polymerization in adhesive bonding of resin to dentin. J Dent Res 70, 1088-1091.

39. Gerzina TM, Hume WR (1995) Effect of hydrostatic pressure on the diffusion of monomers through dentin in vitro. J Dent Res 74, 369-373.

40. Gerzina TM, Hume WR (1996) Diffusion of monomers from bonding resin-resin composite combinations through dentine in vitro. J Dent 24, 125-128.

41. EldenizAU, Mustafa K, Ørstavik D, Dahl JE (2007) Cytotoxicity of new resin-, calcium hydroxideand silicone-based root canal sealers on fibroblasts derived from human gingiva and L929 cell lines. Int Endod J 40, 329-337. 